studies are important to help us understand the controls on climate variability, and to determine whether the current models can successfully reproduce the observed changes. Coupled atmosphere-ocean-vegetation modelling and natural variability will be the major foci of the second phase of the Palaeoclimate Model Intercomparison Project (PMIPII). As well as focusing on the midHolocene, the new project will also perform simulations for the early Holocene (see EOS, 1 October 2002, and http://www-Isee.eea.fr.pmip

At such time-scales, it is also crucial to account for solar forcing (i.e., variations in solar activity) and volcanic eruptions. The ECBILT-MOM model, developed at the KNMI, has been used to examine the phase relationships between solar forcing and the extent of glaciers in the Alps. Studies of the last millennium have also highlighted the importance of a good knowledge of the natural variability in forcing mechanisms (e.g. Collins et al., 2002). Model simulations must include this variability if we are to faithfully test the models. Currently, our knowledge of this forcing is generally rather poor.

The increasing importance of gathering more data and modelling expertise on the global carbon cycle during the Holocene was also stressed. Until recently, most attempts to understand the cause for the $\mathrm{CO}_{2}$ increase during the Holocene were based on conceptual models. With biogeochemical cycles being implemented in models, a more detailed model-data comparison will be possible. Brovkin et al. (2002) recently illustrated the power of such tools by analyzing the consequences of Holocene climate change and change in ocean alkalinity on the terrestrial and oceanic carbon stocks during the Holocene. They also simulated atmospheric $\delta^{13} \mathrm{C}$ concentration to compare it with data and test their hypotheses about alkalinity and lysocline depth-even if in this particular case, $\delta^{13} \mathrm{C}$ data fail to provide sufficient constraint. The alternative approach is to use the model to generate synthetic records. In other words, attempting to reconstruct the raw data seems to be a promising way to better understand how climate worked in the past.

The meeting suggested many future research directions. It also highlighted the importance of studying both past millennium and longer time-scale variability. All of the approaches are valuable for improving our understanding of climate variability and for evaluating climate models. For this latter problem, it is also essential that we build a new database of the natural variability of climate forcing (especially solar and volcanic), as well as building and maintaining databases of high quality climate proxies for the whole of the Holocene period. The increasing ability of the models and improvements in high-resolution data will ensure that the next few years will be an exciting time.

\section{REFERENCES \\ Brovkin, V., Hofmann, M., Bendtsen, J. and Ganopolski, A., 2002: Ocean biology could control atmospheric d13C during glacial-interglacial cycle. Geochemistry Geophysics Geosystems 3: art.no. $-1027$ \\ Claussen, M., Kubatzki, C., Brovkin, V., Ganopolski, V., Hoelzmann, P. and Pachur, H.J., 1999: Simulation of an abrupt change in Saharan vegetation in the mid-Holocene. Geophysical Research Letters 26: 3037-2040 \\ Collins, M., Osborn, T.J., Tett, S.F.B., Briffa, K.R. and Schweingruber, F.H., 2002: A comparison of the variability of a climate model with paleotem- perature estimates from a network of tree-ring densities. Journal of Climate 15: 1497-1515}

Michel Crucifix ${ }^{1}$ and Paul Valdes ${ }^{2}$

${ }^{1}$ Hadley Centre for Climate Prediction and Research, UK:

michel crucific@metoffice.com

2University of Reading, UK;

p.j.valdes@reading.ac.uk

\title{
Investigating Holocene Climate Variability: Data-Model Comparisons
}

\section{ESF/HOLIVAR Meeting. Louvain-LA-Neuve, Belgium, 12-15 June 2002}

Comparing model output with information provided by proxy data was discussed in detail. The comparison is challenging because the characteristics of model output and paleodata are very different and many sources of uncertainty exist. Climate is represented at different spatial scales: local in proxy records, several hundred kilometers or more in models. Further, the registered variability in proxies is only partly caused by climatic variations, so that it is necessary to isolate the climatic signal using statistical methods and to represent the non-climatic residuals (perhaps by a suitable stochastic model). Finally, the responses of the proxies to the local or large-scale climate may be non-invertible. A number of model-proxy compari- son methods were presented at the workshop to address some of these difficulties.

The traditional inverse approach is to reconstruct some aspect of climate from proxy data (often including an aggregation to larger spatial scales more suited for comparison with model output) and then compare the reconstruction to simulated climate data. It was demonstrated during the workshop how the non-climatic residuals influence variance, trends and spatial patterns and that appropriate treatment of these residuals can avoid biased comparisons. Examples were given (Collins et al., 2002) of the comparison, at the inter-decadal time-scale, between levels of internally generated variability simulated during a
GCM (coupled ocean-atmosphere general circulation model) control run, and the temperature variability reconstructed from tree-ring density across the Northern Hemisphere. The results were sensitive to the processing of the tree-ring data but indicated an underestimation of the variability by the model. This could be partly accounted for by the influence of natural external forcing changes (solar irradiance or volcanic aerosols). Comparisons of proxy-based temperature reconstructions with EBM (energy balance model) simulations of the response to natural and anthropogenic forcings (updated from Crowley, 2000) were presented, with the reconstructions used to identify the climate sensitivity that provides the best fit between model and data 


\section{Workshop Reports: $2^{\text {nd }}$ Holivar Workshop}

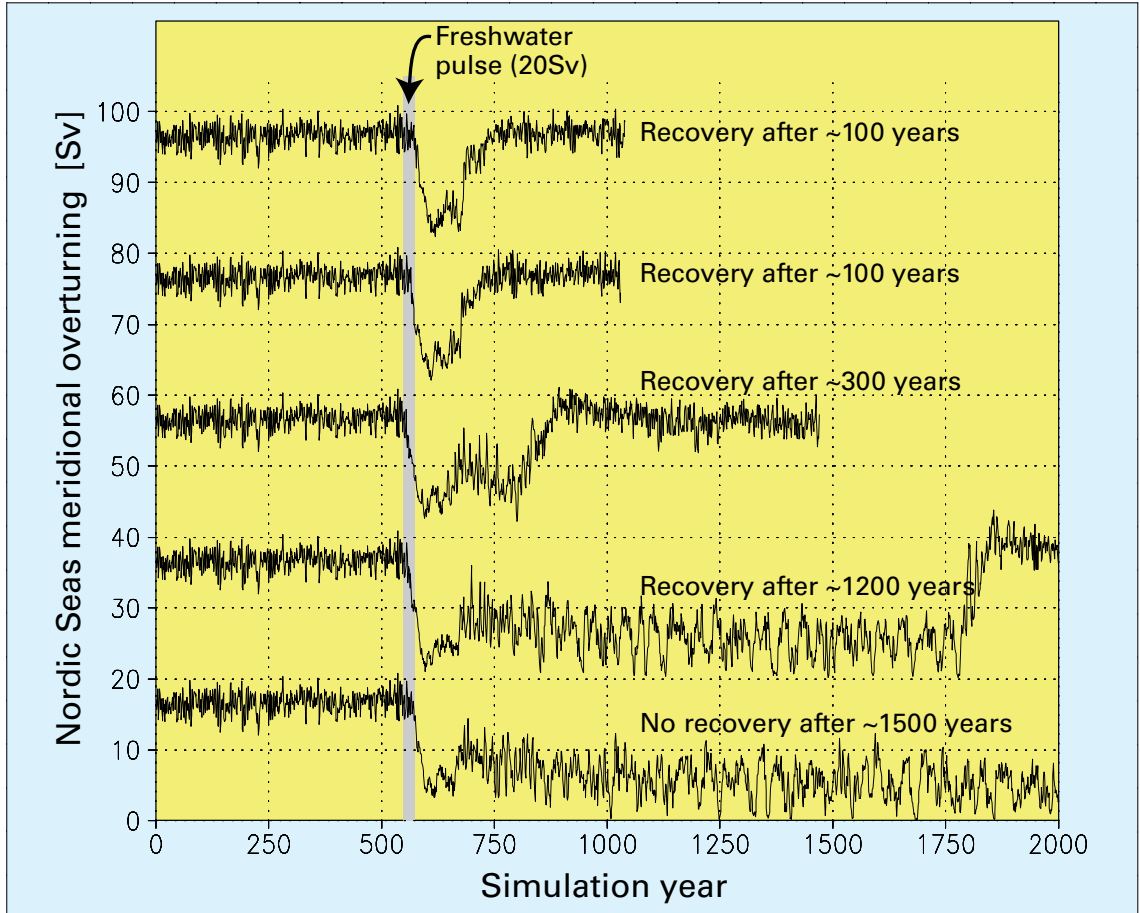

Figure 1: Simulation of the 8.2 ky BP event (Renssen et al., 2002): response of the thermohaline circulation to freshwater pulses of 20 Sv released during simulation years 550-570 in the Labrador Sea, for 5 ensemble members (each offset by 20 Sv for clarity). Other forcings are representative of $8.5 \mathrm{ky} \mathrm{BP}$.

for the past 1000 years. On longer time-scales, both quantitative and qualitative comparisons of proxy data with the climate simulated by GCMs and EMICs (Earth system model of intermediate complexity) were presented, using simulations of time slices, transient simulations of particular events (e.g., Fig. 1 and Renssen et al., 2002) and transient simulations of virtually the whole Holocene (Crucifix et al., 2002; Brovkin et al., 2002).

The workshop participants agreed on the great potential offered by the forward-modeling approach, in which appropriate process-based (physical, biological, chemical) or empirical models are driven by climate model output to simulate a proxy value or time series that is then compared with the actual proxy data. This approach can deal explicitly with non-linear and non-invertible proxy response to multiple climate drivers, and can also aid our understanding of the processes responsible for the proxy behavior. Insufficient development, tuning and validation of process-based models for different proxy types and locations has restricted the application of the forward-modeling approach to date but noteworthy progress was reported at the workshop, in- cluding the simulation of tree rings, ice cores, glacier length and local sea level (e.g., Reichert et al., 2001; Weber and Oerlemans, 2002).

While inverse reconstruction and forward modeling with proxy data allow comparison with model output, presentations were also made of possible methods for the combination of proxy and model data to provide improved estimates of past climate variations. One technique, named DATUN (Data Assimilation Through Upscaling and Nudging, Jones and Widmann, 2002), 'nudges' the climate towards an atmospheric circulation state that has been reconstructed from a set of paleodata, while remaining nearly consistent with the model's physics and the applied external forcings. A second method was proposed (by Mat Collins), whereby many realizations of each simulation year are generated (again under appropriate external forcing variations) and the closest analog to the available paleodata for that year is selected before proceeding to the next year of the simulation. It was proposed to concentrate efforts on specific periods during the Holocene:

-the classical "Little Ice Age" (16 ${ }^{\text {th }}$ to $19^{\text {th }}$ century $A D$ ), -the Sub-Boreal-Sub-Atlantic transition around $850 \mathrm{BC}$ (2750 y BP),

-the termination of the African Humid Period around 6-5 ky BP, and

-the 8.2 ky BP cooling event.

Evidence was presented from proxy data that significant climate change occurred during these periods. The stronger signal-to-noise ratio for these events should make diagnosis of climate behavior more feasible in both data and models. It was noted (Fig. 1) that model studies focusing on these periods should also aim to perform ensemble runs to capture the range of inherent model variability (e.g., Renssen et al., 2002), thereby better allowing the model to encompass the single realization represented by reality (as registered in proxy data).

Discussion made it clear that a hierarchy of modeling studies, including GCMs and EMICs, was considered essential given the uncertain forcings, the need for ensemble simulations, and the complex interactions taking place within and between subsystems of the Earth system. It was proposed that the HOLIVAR program establishes a database of the different model runs covering the Holocene that would be accessible to the scientific community.

Further information is available at http://www.cru.uea.ac.uk/ timo/ holivar/

\section{REFERENCES}

Collins, M., Osborn, T.J., Tett, S.F.B., Briffa, K.R. and Schweingruber, F.H., 2002: A comparison of the variability of a climate model with palaeo-temperature estimates from a network of tree-ring densities. Journal of Climate 15: 1497-1515.

Crowley, T.J., 2000: Causes of climate change over the past 1000 years, Science 289: 270-277

Renssen, H., Goosse, H. and Fichefet, T., 2002: Modeling the effect of freshwater pulses on the early Holocene climate: the influence of high frequency climate variability. Paleoceanography 17, No. 2, 10.1029/2001PA000649.

For full references please consult:

www.pages-igbp.org/products/newsletters/ref2003_2.html

\section{Hans RensSen ${ }^{1}$ and Tim OSBorn ${ }^{2}$}

${ }^{1}$ Universiteit Amsterdam, Netherlands, hans.renssen@falw.vu.nl

${ }^{2}$ University of East Anglia, United Kingdom, t.osborn@uea.ac.uk 